\title{
Trends in anemia management in US hemodialysis patients 2004-2010
}

\author{
Dana C Miskulin ${ }^{1,10^{*}}$, Jing Zhou ${ }^{2,6}$, Navdeep Tangri ${ }^{3}$, Karen Bandeen-Roche ${ }^{4}$, Courtney Cook ${ }^{2}$, Patti L Ephraim ${ }^{5,6}$, \\ Deidra C Crews ${ }^{6,7}$, Julia J Scialla ${ }^{8}$, Stephen M Sozio ${ }^{6,7}$, Tariq Shafi, ${ }^{6,7}$, Bernard G Jaar ${ }^{5,6,7,9}$, L Ebony Boulware ${ }^{2,5,6}$ \\ and for The DEcIDE Network Patient Outcomes in End Stage Renal Disease Study Investigators
}

\begin{abstract}
Background: There have been major changes in the management of anemia in US hemodialysis patients in recent years. We sought to determine the influence of clinical trial results, safety regulations, and changes in reimbursement policy on practice.

Methods: We examined indicators of anemia management among incident and prevalent hemodialysis patients from a medium-sized dialysis provider over three time periods: (1) 2004 to 2006 (2) 2007 to 2009, and (3) 2010. Trends across the three time periods were compared using generalized estimating equations.

Results: Prior to 2007, the median proportion of patients with monthly hemoglobin $>12 \mathrm{~g} / \mathrm{dL}$ for patients on dialysis 0 to 3, 4 to 6 and 7 to 18 months, respectively, was $42 \%, 55 \%$ and $46 \%$ declined to $41 \%, 54 \%$, and $40 \%$ after 2007, and declined more sharply in 2010 to 34\%, 41\%, and 30\%. Median weekly Epoeitin alpha doses over the same periods were 18,000, 12,400, and 9,100 units before 2007; remained relatively unchanged from 2007 to 2009; and decreased sharply in the patients 3-6 and 6-18 months on dialysis to 10,200 and 7,800 units, respectively in 2010. Iron doses, serum ferritin, and transferrin saturation levels increased over time with more pronounced increases in 2010.

Conclusion: Modest changes in anemia management occurred between 2007 and 2009, followed by more dramatic changes in 2010. Studies are needed to examine the effects of declining erythropoietin use and hemoglobin levels and increasing intravenous iron use on quality of life, transplantation rates, infection rates and survival.
\end{abstract}

Keywords: Anemia, Erythropoietin stimulating agents, Hemodialysis

\section{Background}

Efforts to identify an anemia management strategy that optimizes clinical outcomes and quality of life among hemodialysis (HD) patients have received substantial attention in recent years [1,2]. Until recently, ESA use in patients with chronic kidney disease (CKD) had been steadily increasing [3]. Average doses of erythropoiesis stimulating agents (ESAs) in 2006 were threefold higher than they were in 1991 and ESAs accounted for \$2 billion of Medicare expenditures [3]. Such changes occurred despite early

\footnotetext{
* Correspondence: dmiskulin@tuftsmedicalcenter.org

'Division of Nephrology, Tufts University School of Medicine, Boston, MA, USA

${ }^{10}$ Tufts Medical Center, 800 Washington St., Boston, MA 02111, USA

Full list of author information is available at the end of the article
}

experiences indicating that there was an increased risk of thromboembolic events, worsened hypertension, and seizures with treatment with ESAs. In 2006, a major trial found an increased risk of cardiovascular events and death of treating CKD patients to higher versus lower $\mathrm{Hb}$ targets [4]. Two other trials, one involving HD patients and published in 1998 [5], and the other, involving CKD patients and also published in late 2006 [6], reported no benefit with treating to higher $\mathrm{Hb}$ values.

In response to these findings and studies showing an increase in cancer deaths in oncology patients, the U.S. Food and Drug Administration (FDA) issued a black box warning on ESA labels in March 2007, recommending ESAs be used at the lowest possible dose to avoid transfusion [7]. At this same time, a short term, randomized trial found that

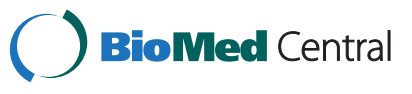


treatment with $1 \mathrm{~g}$ of intravenous (IV) iron in patients with serum ferritin 500-1000 and TSat $<25 \%$ led to a significant increase in $\mathrm{Hb}$ and decline in EPO dose [8]. In late 2009, a fourth major of targeting a high vs. lower $\mathrm{Hb}$ was published, and showed an increase in stroke (a secondary endpoint) with targeting higher $\mathrm{Hb}$ values in CKD patients [9]. The FDA issued new safety regulations, requiring that ESAs be prescribed under a risk evaluation and mitigation program [10].

Recent changes to reimbursement for dialysis care may have also influenced practice. Prior to January 1, 2011, the Centers for Medicare and Medicaid Services (CMS) reimbursed dialysis facilities for ESAs at the average wholesale price plus 6 percent [11]. In August 2010, CMS announced the final rules for the ESRD Prospective Payment System (ESRD PPS) or bundled payment system, under which injectable medications administered in HD units, including ESAs, each be reimbursed at a fixed rate, regardless of dose, beginning January 1, 2011 [11].

We sought to determine the potential influence of clinical trial results and changes in safety regulations with changes in reimbursement policies on anemia management practices in a representative U.S. HD population.

\section{Methods}

\section{Study population}

We performed a series of cross-sectional analyses to characterize patterns of anemia management during the first 18 months of HD from 2004 to 2010 in Dialysis Clinic, Inc (DCI), a medium-sized not-for-profit US dialysis provider with approximately 200 dialysis units across the US. We included patients who survived at least three months from the time of dialysis initiation, had at least one HD treatment and at least one hemoglobin $(\mathrm{Hb})$ measurement. We excluded patients who received peritoneal dialysis or home HD between 2004 and 2010.

\section{Data}

We obtained data from DCI's electronic medical information system. Laboratory measures for $\mathrm{Hb}$, serum ferritin, iron and transferrin had been processed at the DCI Central Laboratory (Nashville, TN), which is certified by the Clinical Laboratory Improvement Amendments. We calculated TSat using the formula: (TSat = iron/transferrin*70.9). If more than one value of a laboratory parameter (e.g., $\mathrm{Hb}$ ) existed in a month, we took the median of all values. The cumulative IV iron dose per month was calculated as the sum of iron dextran, iron sucrose or iron gluconate administered each month. If there was no record of IV iron administered for a treatment, the dose was zero. The median weekly EPO dose per month was calculated as the cumulative weekly EPO dose first, and then we took the median of the weekly doses over the month. The study was conducted in accordance with the Declaration of Helsinki and was approved by the Johns Hopkins Medicine Institutional Review Board (Baltimore, Maryland).

\section{Statistical analysis}

We stratified analyses according to patients' time on HD (i.e. 0-3, 4-6 and 7-18 months after starting HD) to account for differences in ESA and iron dosing at dialysis initiation when patients often require more ESA and iron than later on.

We examined trends in anemia management over three time periods: 1) 2004-2006; 2) 2007-2009, which follows the publication of a major trial showing harm with targeting a higher $\mathrm{Hb}$ in $\mathrm{CKD}$ patients and another showing no benefit $[4,6]$ as well as the FDA's issuance of a black box warning on the EPO label advising against targeting higher $\mathrm{Hb}$ levels [7]; and 3) 2010, which follows publication of another trial showing increase in strokes with treating CKD patients to a higher $\mathrm{Hb}$ target [9] and release of the Final Rule for a bundled CMS payment system [11] to be enacted January 1, 2011. To examine whether the changes in anemia management between time periods were statistically significant, we modeled the anemia parameters for each individual using generalized estimating equations (GEE) models which account for 'within subject' as well as 'between clinic' correlations. $\mathrm{Hb}>12 \mathrm{~g} / \mathrm{dL}$ and $\mathrm{Hb}<10 \mathrm{~g} / \mathrm{dL}$ were modeled as binary outcomes, and ferritin, TSat, and EPO dose were modeled as continuous outcomes. To examine the trends in IV iron doses overtime, we used two-stage GEE models as a substantial proportion of patients did not receive IV iron in a given month. In the first stage, we modeled the binary outcome of "any" versus "zero" doses; and for the second stage we modeled iron dose as a continuous variable, among those receiving iron. We created linear spline terms with knots at January 2007 and January 2010 to test for differences in the initial values (i.e. intercepts) and rates of change (i.e. slopes) during the three time periods (2004-2006, 2007-2009 and 2010). We adjusted all models for age, race/ethnicity, gender, and diabetes status. Analyses were conducted using SAS 9.2 (Cary, NC).

\section{Results}

\section{Study population}

We observed anemia management practices among $12,281,13,288$, and 6,142 patients who dialyzed between 2004-2006, 2007-2009 and 2010, respectively, at dialysis units within Dialysis Clinic Inc, (DCI). Patient characteristics across the three time periods were similar to those of patients initiating dialysis across the US, with the exception of a higher proportion of African American (36\% vs. $28 \%$ ) and a lower proportion of Hispanics (6\% 
vs. 14\%) [3]. The proportion of the study population that was African American or Hispanic, 45-64 years old, and with 'other' causes of ESRD, increased over the three time periods (Table 1).

\section{Unadjusted trends in anemia management}

Per Table 2 we find that the percent of patients with $\mathrm{Hb}$ $>12$ g/dL decreased between 2004-2006 and 2007-2009 and fell even more sharply in 2010. This was accompanied by an increase in $\mathrm{Hb}<10 \mathrm{~g} / \mathrm{dL}$ and a parallel decrease in the percent of patients with a $\mathrm{Hb}>12 \mathrm{~g} / \mathrm{dL}$. Median Epoetin Alfa (EPO) doses were similar over 2004 to 2006 and 2007-2009 but decreased dramatically in 2010. The percentage of patients receiving monthly intravenous (IV) iron also was lower in 2010, compared to the periods before 2007. However, among patients who received IV iron, the median doses were higher between 2007 to 2009 and in 2010 compared to before 2007. Median values of serum ferritin, and transferrin saturation (TSat) also increased across periods.

\section{Time trends in anemia management Hemoglobin}

Results are described separately by subgroups defined by the time since starting dialysis (0-3, 4-6, 7-18 months), as trends were different depending on dialysis vintage. Between
January 2004 and December 2006, the percentage of patients with $\mathrm{Hb}>12 \mathrm{~g} / \mathrm{dL}$ increased among patients on dialysis for $0-3,4-6$, and 7-18 months, from 33 to $41 \%$, 45 to $56 \%$, 45 to $51 \%$, respectively, but declined between $2007-$ 2009 and by the end of 2009, were at values seen back in 2004. The proportion with $\mathrm{Hb}>12 \mathrm{~g} / \mathrm{dL}$ fell more sharply in 2010 except in new patients $0-3$ months on dialysis where there was an increase in $\mathrm{Hb}>12 \mathrm{~g} / \mathrm{dL}$ (Figure 1a).

The changes in the frequency of $\mathrm{Hb}<10 \mathrm{~g} / \mathrm{dL}$ (Figure 1b) were the opposite of the trends described above for $\mathrm{Hb}>12 \mathrm{~g} / \mathrm{dL}$, with a decrease in $\mathrm{Hb}<10 \mathrm{~g} / \mathrm{dL}$ between 2004-2006, an increase between 2007-2009 and further increases in 2010, such that by December, 2010, 17\% of patients who had been receiving dialysis for $0-3$ months, $5 \%$ of patients dialyzed for 4 to 6 , months and $7 \%$ of patients dialyzed for 7-18 months had a $\mathrm{Hb}<10 \mathrm{~g} / \mathrm{dL}$. Changes in the frequency of $\mathrm{Hb}>12 \mathrm{~g} / \mathrm{dL}$ and $\mathrm{Hb}<10 \mathrm{~g} / \mathrm{dL}$ across the 3 periods were statistically significant for all comparisons except for the change in $\mathrm{Hb}<10 \mathrm{~g} / \mathrm{dL}$ between 2007-2009 and 2010 in the subgroup of patients who had been dialyzing for 4-6 months.

\section{Epoetin alfa utilization}

Weekly EPO dose was essentially unchanged between 2004 and 2006 (Figure 1c). Between 2007-2009, EPO dose increased from 19,133 to 21,805 units among patients

Table 1 Patient characteristics, by time period

\begin{tabular}{|c|c|c|c|c|c|}
\hline & & \multicolumn{4}{|c|}{ Years } \\
\hline & & 2004-2006 & 2007-2009 & 2010 & p-value ${ }^{1}$ \\
\hline Total no. (N) & & 12,281 & 13,288 & 6,142 & $<0.01$ \\
\hline Age at first dialysis treatment at DCl, mean (SD) & & $62.2(15.4)$ & $62.0(15.3)$ & $61.9(15.3)$ & 0.35 \\
\hline \multirow[t]{3}{*}{ Age category at first dialysis treatment at DCI, N (\%) } & $18-44$ & $1,773(14.4)$ & $1,882(14.2)$ & $864(14.1)$ & $<0.01$ \\
\hline & $45-64$ & $4,736(38.6)$ & $5,374(40.4)$ & $2,546(41.5)$ & \\
\hline & $\geq 65$ & $5,772(47.0)$ & $6,032(45.4)$ & $2,732(44.5)$ & \\
\hline \multirow[t]{2}{*}{ Sex, N (\%) } & Male & $6,854(55.8)$ & $7,439(56.0)$ & $3,452(56.2)$ & 0.88 \\
\hline & Female & $5,427(44.2)$ & $5,849(44.0)$ & $2,690(43.8)$ & \\
\hline \multirow[t]{4}{*}{ Race, N (\%) } & African American & $4,357(35.5)$ & $4,766(35.9)$ & $2,264(36.9)$ & $<0.01$ \\
\hline & White & $7,050(57.4)$ & $7,550(56.8)$ & $3,425(55.8)$ & \\
\hline & Other $^{2}$ & $802(6.5)$ & $867(6.5)$ & $377(6.1)$ & \\
\hline & Unknown & $72(0.6)$ & $105(0.8)$ & $76(1.2)$ & \\
\hline \multirow[t]{3}{*}{ Ethnicity, N (\%) } & Hispanic & $682(5.6)$ & $828(6.2)$ & $421(6.9)$ & $<0.01$ \\
\hline & Non-Hispanic & $11,535(93.9)$ & $12,308(92.6)$ & $5,598(91.1)$ & \\
\hline & Unknown & $64(0.5)$ & $152(1.1)$ & $123(2.0)$ & \\
\hline \multirow[t]{5}{*}{ Primary cause of ESRD, N (\%) } & Diabetes & $5,529(45.0)$ & $6,001(45.2)$ & $2,771(45.1)$ & 0.03 \\
\hline & Hypertension & $3,511(28.6)$ & $3,847(29.0)$ & $1,758(28.6)$ & \\
\hline & Glomerulonephritis & $1,152(9.4)$ & $1,121(8.4)$ & $526(8.6)$ & \\
\hline & Other & $2,045(16.7)$ & $2,284(17.2)$ & $1,078(17.6)$ & \\
\hline & Unknown & $44(0.4)$ & $35(0.3)$ & $9(0.2)$ & \\
\hline
\end{tabular}


Table 2 Anemia management parameters by time on dialysis and dialysis incidence year

\begin{tabular}{|c|c|c|c|c|}
\hline & \multirow{2}{*}{$\begin{array}{l}\text { Time on } \\
\text { dialysis }\end{array}$} & \multicolumn{3}{|c|}{ Incidence year } \\
\hline & & 2004-2006 & 2007-2009 & 2010 \\
\hline \multirow[t]{3}{*}{ Hemoglobin (g/dl), Median (Q25, Q75) } & $0-3$ month & $11.7(10.4,12.9)$ & $11.6(10.3,12.8)$ & $11.4(10.0,12.5)$ \\
\hline & $3-6$ month & $12.3(11.3,13.2)$ & $12.3(11.4,13.0)$ & $12.0(11.2,12.7)$ \\
\hline & 6-18 month & $12.1(11.2,12.9)$ & $11.9(11.1,12.7)$ & $11.8(10.9,12.5)$ \\
\hline \multirow[t]{3}{*}{ Percent with Hemoglobin <10 (monthly), Median (Q25, Q75) } & $0-3$ month & $12.8(8.2,30.4)$ & $13.3(7.6,34.0)$ & $17.1(9.3,42.8)$ \\
\hline & $3-6$ month & $7.0(6.6,7.1)$ & $6.7(6.5,7.4)$ & $7.7(6.6,8.0)$ \\
\hline & 6-18 month & $6.2(6.0,6.5)$ & $6.8(6.5,6.9)$ & $8.9(8.3,9.3)$ \\
\hline \multirow[t]{3}{*}{ Percent with Hemoglobin > 12 (monthly), Median (Q25, Q75) } & $0-3$ month & $42.0(17.8,57.1)$ & $40.6(14.5,57.4)$ & $33.6(9.08,49.5)$ \\
\hline & $3-6$ month & $54.9(50.5,58.7)$ & $54.2(49.8,58.2)$ & $41.2(35.8,48.4)$ \\
\hline & 6-18 month & $45.9(44.6,49.7)$ & $39.9(36.9,46.1)$ & $29.5(25.7,35.9)$ \\
\hline \multirow[t]{3}{*}{ Weekly ESA doses (Unit), Median (Q25, Q75) } & $0-3$ month & $18000(9000,30000)$ & $20000(9000,30600)$ & $18000(8000,30000)$ \\
\hline & $3-6$ month & $12400(4800,24000)$ & $13500(4800,25200)$ & $10200(2600,21000)$ \\
\hline & $6-18$ month & $9100(3900,19500)$ & $9600(3900,20100)$ & $7800(2400,16800)$ \\
\hline \multirow[t]{3}{*}{ Percent of patients receiving monthly IV iron, Median (Q25, Q75) } & $0-3$ month & $71.1(62.5,72.5)$ & $77.8(67.9,78.5)$ & $76.0(72.6,77.4)$ \\
\hline & $3-6$ month & $71.0(69.7,72.0)$ & $74.5(73.6,76.2)$ & $70.3(68.9,73.6)$ \\
\hline & $6-18$ month & $65.7(64.5,68.2)$ & $67.4(65.9,70.4)$ & $60.6(58.1,62.2)$ \\
\hline \multirow[t]{3}{*}{ Monthly iron doses (mg) for those who had received iron, Median (Q25, Q75) } & $0-3$ month & $400(200,800)$ & $475(200,800)$ & $500(300,850)$ \\
\hline & $3-6$ month & $300(200,500)$ & $300(200,500)$ & $400(200,600)$ \\
\hline & 6-18 month & $200(125,400)$ & $225(125,400)$ & $300(200,500)$ \\
\hline \multirow[t]{3}{*}{ TSat(\%), Median (Q25, Q75) } & $0-3$ month & $18.4(13.7,24.8)$ & $18.3(13.9,24.5)$ & $21.5(16.1,28.4)$ \\
\hline & $3-6$ month & $22.6(17.0,30.3)$ & $22.6(17.2,30.0)$ & $24.4(19.1,32.8)$ \\
\hline & 6-18 month & $23.6(18.3,30.5)$ & $23.6(18.4,30.5)$ & $25.6(20.3,33.3)$ \\
\hline \multirow[t]{3}{*}{ Ferritin (ng/ml), Median (Q25, Q75) } & $0-3$ month & $284(136,533)$ & $312(157,566)$ & $354(179,624)$ \\
\hline & $3-6$ month & $447(243,687)$ & $499(287,744)$ & $600(360,858)$ \\
\hline & 6-18 month & $592(376,796)$ & $654(436,893)$ & $707(474,996)$ \\
\hline
\end{tabular}




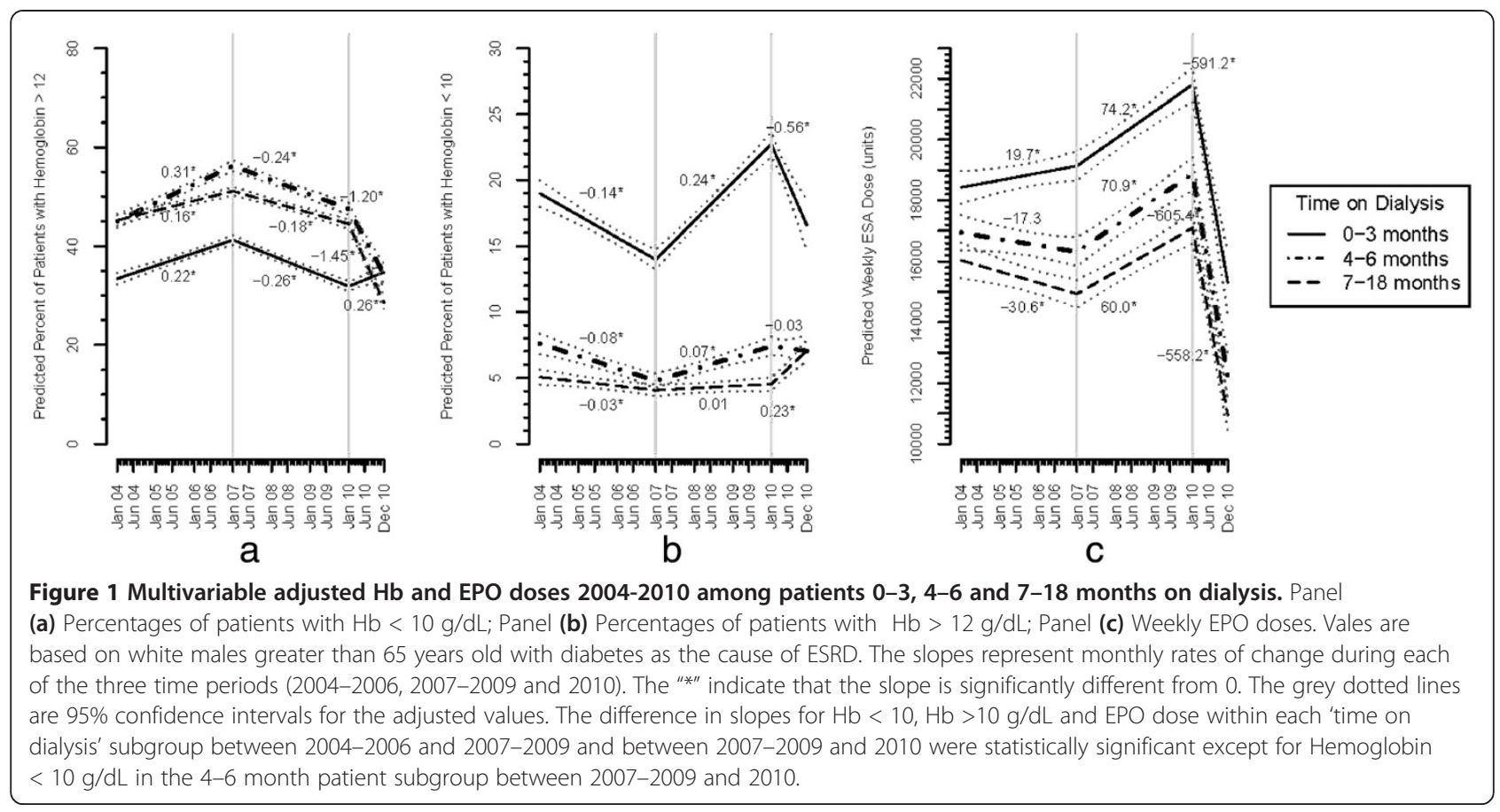

dialyzing for $0-3$ months, 16,317 to 18,870 units among patients dialyzing 4-6 months and 14,931 to 17,091 units among patients dialyzing 7-18 months. Doses declined sharply in 2010 to $15,302,12,211$ and 10,951 units in these same groups, respectively, which represents a 30\%, 35\% and $36 \%$ decline. The rates of change in EPO dose across the three time periods were statistically significant in each subgroup.

\section{Intravenous iron therapy}

Between January 2004 and December 2006, the percentage of patients receiving monthly IV iron, increased from $70 \%$ to $74 \%, 70 \%$ to $74 \%$, and $69 \%$ to $71 \%$ among patients who had been treated with HD for $0-3,4-6$ and 7-18 months, respectively. There were small increases in each of the three subgroups between 2007-2009 and a small decline in 2010.
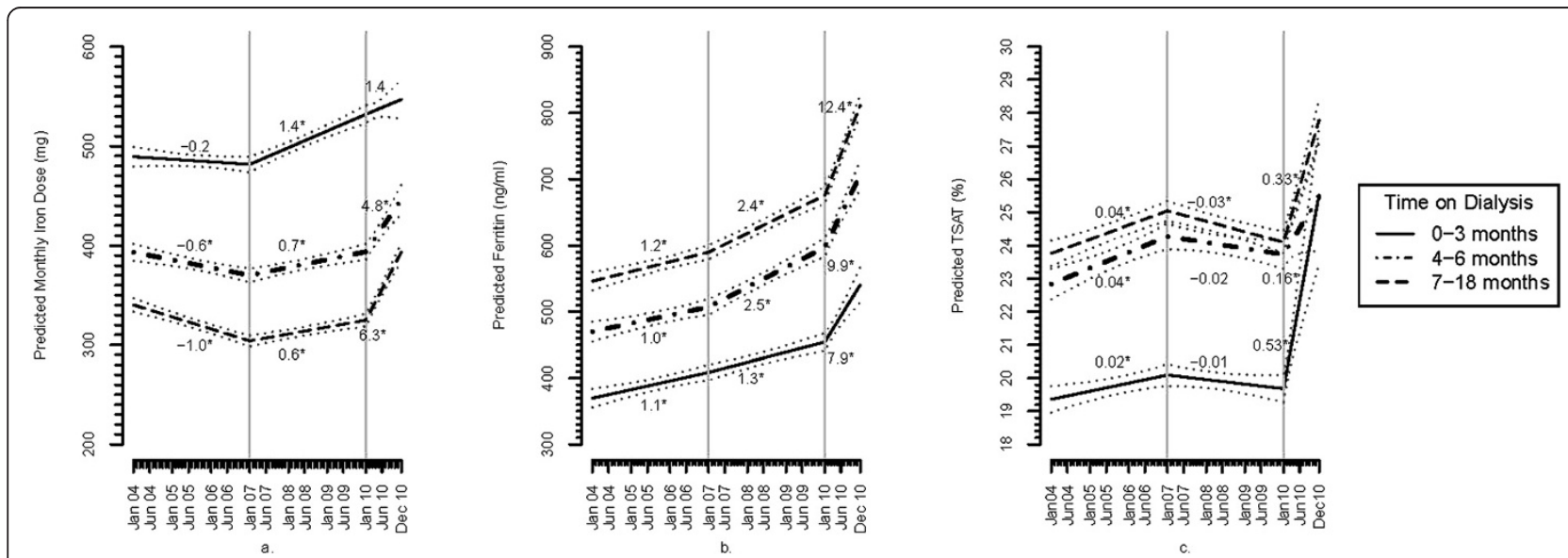

Figure 2 Multivariable adjusted iron doses and markers of iron stores 2004-2010 among patients 0-3, 4-6, and 7-18 months on dialysis. Panel (a) Monthly iron dose (mg); Panel (b) Serum ferritin ( $\mathrm{ng} / \mathrm{ml})$; Panel (c) TSat (\%). Values are based on white males greater than 65 years old with diabetes as the cause of ESRD. The slopes represent monthly rates of change for each of the three time periods (2004-2006, 2007-2009 and 2010). The "** indicate that the slope is significantly different from 0 . The grey dotted lines are $95 \%$ confidence intervals for the predicted values. The difference in slopes between 2004-2006 and 2007-2009 and between 2007-2009 and 2010 are statistically significant within each 'time on dialysis' subgroup for each of the parameters except for the comparisons of monthly iron dose in the 0-3 month subgroup between 2007-2009 and 2010, and ferritin in the 0-3 month subgroup between 2004-2006 and 2007-2009. 
Per Figure $2 \mathrm{a}$, among patients receiving iron, there was no clinically meaningful change in monthly IV iron doses between 2004 to 2006 or between 2007 to 2009. Between January 2010 and December 2010, the adjusted monthly IV iron dose increased from 532 to 547,394 to 446 and 325 to $394 \mathrm{mg}$ respectively, among patients $0-3,4-6$ and 7-18 months on dialysis. The increase in iron dose before and after 2010 was statistically significant in the prevalent subgroups (dialyzing 4-6 and 7-18 months).

\section{Transferrin saturation and ferritin}

There was no significant change in multivariable adjusted TSat values between 2004-2006 and 2007-2009 for any subgroup by time on dialysis (Figure 2b). Between January and December 2010, there were statistically significant increases in TSat values from $20 \%$ to $26 \%, 24 \%$ to $25 \%$ and $24 \%$ to $28 \%$ in patients $0-3,4-6$, and 7-18 months on dialysis.

Serum ferritin steadily increased from 2004 through the end of 2010 in each of the subgroups (Figure 2c), with changes of 370 to $541 \mathrm{mg}, 470$ to 707 , and 546812 $\mathrm{ng} / \mathrm{ml}$, in patients who had received dialysis for $0-3,4-6$ and 7-18 months, respectively. The rates of change in TSat and serum ferritin levels across the 3 time periods were statistically significant for all subgroups except for ferritin in the incident patients (dialyzing 0-3 months) between 2004-2006 and 2007-2009.

\section{Discussion}

Our results suggest that the 2006 publication of a clinical trial demonstrating harm with targeting higher $\mathrm{Hb}$ levels [4] and the FDA's issuance of a black box warning on the epoeitin label [7] led to relatively modest changes in anemia management as compared with the much sharper declines in $\mathrm{Hb}$ and EPO doses that were seen in 2010 after publication of another trial showing harm with higher $\mathrm{Hb}$ values [9] and CMS's release of the final rule for a revised payment system [11]. Over the course of 2010, there was a nearly $30 \%$ decline in the proportion of patients with $\mathrm{Hb}$ greater than $12 \mathrm{~g} / \mathrm{dL}$ and a more than $30 \%$ decline in median EPO doses.

Our observations are consistent with the USRDS Annual Data Report [12], which showed more dramatic reductions in EPO doses and in the proportion of patients with $\mathrm{Hb}$ levels greater than $12 \mathrm{~g} / \mathrm{dL}$ in 2010 than in earlier years. It is impossible to tell whether these changes in anemia management practices were influenced more by the publication of a second major trial showing harm with targeting a higher $\mathrm{Hb}$ value or preparations for bundled payment policies for dialysis care, as the two occurred at the same time. Practice may not have changed following publication of a major trial showing harm with targeting high $\mathrm{Hb}$ in late 2006 because it was conducted in CKD patients and nephrologists may have considered that these results did not apply to HD patients. However, if this was the explanation, the TREAT trial, published in late 2009, should also not have led to the large changes in practice seen in 2010, as it was also conducted in CKD patients. These findings may suggest that US dialysis units may be much more sensitive to changes in payment policies than research findings and FDA regulations. We speculate that the changes in payment policies likely reinforced and incentivized clinicians' further modifications to their practice patterns to achieve still lower hemoglobin levels through 2010, primarily through more sparing use of EPO. The immediate and dramatic declines in EPO use observed in our study reflect the high costs of EPO, as well as dialysis organizations' motivation and ability to minimize use of costly ESAs while achieving appropriate anemia management goals through centralized prescribing protocols [13].

Only a small proportion of patients had $\mathrm{Hb}$ values less than $10 \mathrm{mg} / \mathrm{dl}$ in 2010, though these data predate changes in the CMS Quality Incentive Program (QIP), under which the penalty for $\mathrm{Hb}$ values falling below $10 \mathrm{~g} / \mathrm{dL}$ was removed in 2013 [14]. Per data from the US Dialysis Outcomes and Practice Patterns Study (DOPPS) EPO doses have continued to decline through 2011, as has the prevalence of $\mathrm{Hb}$ less than $10 \mathrm{~g} / \mathrm{dL}$ [15]. An increase in blood transfusions, longer transplant waiting times as a result of sensitization, as well as declines in physical functioning, cognition and health-related quality of life are potential consequences of a decline in $\mathrm{Hb}$ values in the HD population. It is clear that some patients would be willing to accept higher risks of harms (e.g., stroke, myocardial infarction or death) in return for improved cognitive and physical functioning. To individualize anemia management, we need sensitive measures of cognition, physical health and quality of life as well as open discussion among physicians and their patients about their values and preferences. Attention toward patients' preferences regarding the potential tradeoffs associated with anemia management strategies may be particularly pertinent in light of the downward shift in distribution of $\mathrm{Hb}$ levels that we observed and we anticipate will continue, with the removal of the QIP penalty for $\mathrm{Hb}$ less than $10 \mathrm{~g} / \mathrm{dL}$ in 2013 [14].

Our study is strengthened by its examination of several years of anemia management in a large, representative US dialysis population. We are unaware of other studies explicitly exploring the influence of secular events on trends in anemia management. Our study also has limitations. DCI is a not-for-profit dialysis provider, which may respond differently to secular factors than for-profit dialysis providers. We suspect this is not the case, however, as the general trends reported in this study are similar to those reported by the USRDS [16]. We do not examine trends in practice beyond 18 months after starting dialysis, as at the time of data extraction, 
the number of patients in recent years with more prolonged follow-up was limited. It is possible that the trends seen here are not applicable to very prevalent patients (greater than 18 months after starting dialysis). Although we attempted to describe trends in anemia management in relation to secular events, we cannot make causal inferences, as clinical trial publications overlapped with changes in product label regulations and in reimbursement. Nonetheless, we believe our detailed description of changes in several key indices of anemia management in relation to the publication of major clinical trial results, and changes in regulatory and reimbursement policies, provide insight into numerous potential influences that affect anemia management and patient outcomes.

\section{Conclusion}

In conclusion, modest changes in anemia management occurred after 2007, with more substantial changes after 2010. Both scientific evidence indicating harms with targeting higher $\mathrm{Hb}$ levels, and changes in dialysis reimbursement policies appear to have been associated with these changes, though more dramatic changes coincided with the latter. Study of the effects of treating to lower $\mathrm{Hb}$ values, and the use of less ESA and more IV iron, on morbidity, mortality, transplant waiting times, and health related quality of life are needed.

\section{Competing interests}

The authors declare that they have no competing interests.

\section{Authors' contributions}

DM, NT, LEB, DC, contributed to conception and design, interpretation and drafting the manuscript and gave final approval for submission to be published. DC, JS, SS, TS and BJ contributed to conception and design, interpretation of results and edited the manuscript for important intellectual content. PE acquired the data and contributed to design and interpretation of results. JZ, CC and KB-R contributed to design, and conducted analyses, assisted with interpretation and to writing and editing the draft. All authors read and approved the final manuscript.

\section{Acknowledgements}

The Developing Evidence to Inform Decisions about Effectiveness (DEcIDE) Network Patient Outcomes in ESRD Study was supported by the Agency for Healthcare Research and Quality (AHRQ) contract HHSA2902005003411, Task Order \#6.

The DEcIDE Network Patient Outcomes in End-Stage Renal Disease Study Team consists of members from the Johns Hopkins University, Baltimore (L. Ebony Boulware, Karen Bandeen-Roche, Courtney Cook, Josef Coresh, Deida Crews, Patti Ephraim, Bernard Jaar, Jeonyong Kim, Yang Liu, Jason Luly, Aidan McDermott, Wieneke Michels, Paul Scheel, Tariq Shafi, Stephen Sozio, Albert Wu, Jing Zhou); University of California, San Francisco (Neil R. Powe); the Chronic Disease Research Group, Minneapolis (Allan Collins, Robert Foley, David Gilbertson, Haifeng Go, Brooke Heubner, Charles Herzog, Jiannong Liu, Wendy St. Peter); Cleveland Clinic Foundation (Joseph Nally, Susana Arrigain, Stacey Jolly, Vicky Konig, Xiaobo Liu, Sankar Navaneethan, Jesse Schold,); University of New Mexico, Albuquerque (Philip Zager); Tufts University, Boston (Dana Miskulin, Klemens Meyer); University of Miami (Julia Scialla); University of Manitoba (Navdeep Tangri); and Academic Medical Center, The Netherlands (Wieneke Michels).

Dr. Shafi was supported by National Institute of Diabetes \& Digestive \& Kidney Diseases Grant K23-DK-083514. Dr. Crews was supported by the Amos Medical Faculty Development Program of the Robert Wood Johnson
Foundation, Princeton NJ. Dr. Michels was supported by a Postdoctoral Full Fellowship Abroad Grant (KFB 11.005) of the Dutch Kidney Foundation (Nierstichting), Amerstdam, The Netherlands.

Dr. Scialla was supported by National Institute of Diabetes \& Digestive \& Kidney Diseases Grant K23 DK095949.

The authors express their gratitude to the staff and patients of Dialysis Clinic, Inc.

\section{Disclosures}

Identifiable information, on which this report, presentation, or other form of disclosure is based, is confidential and protected by federal law, Section 903 (c) of the Public Health Service Act, 42 USC 299a-1(c). Any identifiable

information that is knowingly disclosed is disclosed solely for the purpose for which it has been supplied. No identifiable information about any individual supplying the information or described in it will be knowingly disclosed except with the prior consent of that individual.

The results presented in this paper have not been published previously in whole or part, except in abstract format.

\section{Author details}

${ }^{1}$ Division of Nephrology, Tufts University School of Medicine, Boston, MA, USA. ${ }^{2}$ Division of General Internal Medicine, Johns Hopkins School of Medicine, Baltimore, MD, USA. ${ }^{3}$ Division of Nephrology, University of Manitoba, Winnipeg, Manitoba, Canada. ${ }^{4}$ Department of Biostatistics, Johns Hopkins Bloomberg School of Public Health, Baltimore, MD, USA.

${ }^{5}$ Department of Epidemiology, Johns Hopkins Bloomberg School of Public Health, Baltimore, MD, USA. ${ }^{6}$ Welch Center for Prevention, Epidemiology, and Clinical Research, Johns Hopkins Medical Institutions, Baltimore, MD, USA. ${ }^{7}$ Division of Nephrology, Johns Hopkins University School of Medicine, Baltimore, MD, USA. ${ }^{8}$ Department of Medicine, University of Miami School of Medicine, Miami, FL, USA. ' Nephrology Center of Maryland, Baltimore, MD, USA. ${ }^{10}$ Tufts Medical Center, 800 Washington St., Boston, MA 02111, USA.

Received: 23 July 2013 Accepted: 20 November 2013 Published: 1 December 2013

\section{References}

1. Remuzzi $G$, Ingelfinger JR: Correction of anemia-payoffs and problems. N Engl J Med 2006, 355:2144-2146.

2. Unger EF, Thompson AM, Blank MJ, Temple R: Erythropoiesis-stimulating agents-time for a reevaluation. N Engl J Med 2010, 362:189-192.

3. US Renal Data System: USRDS 2008 Annual Data Report: Atlas of Chronic Kidney Disease and End-Stage Renal Disease in the United States. Bethesda, MD: National Institutes of Health, National Institute of Diabetes and Digestive and Kidney Diseases; 2008.

4. Singh AK, Szczech L, Tang KL, Barnhart H, Sapp S, Wolfson M, Reddan D, Investigators C: Correction of anemia with epoetin alfa in chronic kidney disease. N Engl J Med 2006, 355(20):2085-2098.

5. Besarab A, Bolton WK, Browne JK, Egrie JC, Nissenson AR, Okamoto DM, Schwab SJ, Goodkin DA: The effects of normal as compared with low hematocrit values in patients with cardiac disease who are receiving hemodialysis and epoetin. N Engl J Med 1998, 339:584-590.

6. Drüeke TB, Locatelli F, Clyne N, Eckardt KU, Macdougall IC, Tsakiris D, Burger $\mathrm{HU}$, Scherhag A, CREATE Investigators: Normalization of hemoglobin level in patients with chronic kidney disease and anemia. N Engl J Med 2006, 355(20):2071-2084

7. March 2007 PROCRIT ${ }^{\oplus}$ US PI including CHOIR and AOC updates. [http:// www.accessdata.fda.gov/drugsatfda_docs/label/2007/103234s5122lbl.pdf] Accessed Nov 25, 2013.

8. Coyne DW, Kapoian T, Suki W, Singh AK, Moran JE, Dahl NV, Rizkala AR, Group DS: Ferric gluconate is highly efficacious in anemic hemodialysis patients with high serum ferritin and low transferrin saturation: results of the Dialysis Patients' Response to IV Iron with Elevated Ferritin (DRIVE) Study. J Am Soc Nephrol 2007, 18(3):975-984.

9. Pfeffer MA, Burdmann EA, Chen CY, Cooper ME, de Zeeuw D, Eckardt KU, Feyzi JM, Ivanovich P, Kewalramani R, Levey AS, Lewis EF, McGill JB, McMurray JJ, Parfrey P, Parving HH, Remuzzi G, Singh AK, Solomon SD, Toto R, TREAT Investigators: A trial of darbepoetin alfa in type 2 diabetes and chronic kidney disease. N Engl J Med 2009, 361:2019-2032.

10. FDA Drug Safety Communication: Modified dosing recommendations to improve the safe use of Erythropoiesis-Stimulating Agents (ESAs) in chronic 
kidney disease. [http://www.fda.gov/Drugs/DrugSafety/ucm259639.htm] (accessed Nov 25, 2013).

11. The Federal Register Vol. 75 No.155: 42 CFR Parts 410, 413 and 414 Medicare Program; End-Stage RenalDisease Prospective Payment System; Final Rule and Proposed Rule. [http://www.gpo.gov/fdsys/pkg/FR-2010-08-12/pdf/201018466.pdf) (Accessed Nov 25, 2013).

12. U S Renal Data System: USRDS 2012 Annual Data Report: Atlas of Chronic Kidney Disease and End-Stage Renal Disease in the United States. Bethesda, MD: National Institutes of Health, National Institute of Diabetes and Digestive and Kidney Diseases; 2012.

13. Miskulin DC, Weiner DE, Tighiouart $H$, Ladik V, Servilla K, Zager PG, Martin A, Johnson HK, Meyer KB: Computerized decision support for EPO dosing in hemodialysis patients. Am J Kidney Dis 2009, 54:1081-1088.

14. The Federal Register Vol.76 No. 218. 42 CFR Parts 413 and 414 Medicare Program; End-Stage Renal Disease Prospective Payment System and Quality Incentive Program. [http://www.gpo.gov/fdsys/pkg/FR-2011-11-10/pdf/201128606.pdf] (accessed July 2, 2013).

15. Fuller DS, Pisoni R, Bieber BA, Gillespie B, Robinson B: The DOPPS practice monitor for US dialysis care: trends through December 2011. Am J Kidney Dis 2013, 61:342-346.

16. U.S. Renal Data System, USRDS 2013 Annual Data Report: Atlas of Chronic Kidney Disease and End-Stage Renal Disease in the United States. Bethesda, MD: National Institutes of Health, National Institute of Diabetes and Digestive and Kidney Diseases; 2013.

doi:10.1186/1471-2369-14-264

Cite this article as: Miskulin et al.: Trends in anemia management in US hemodialysis patients 2004-2010. BMC Nephrology 2013 14:264.

\section{Submit your next manuscript to BioMed Central and take full advantage of:}

- Convenient online submission

- Thorough peer review

- No space constraints or color figure charges

- Immediate publication on acceptance

- Inclusion in PubMed, CAS, Scopus and Google Scholar

- Research which is freely available for redistribution

Submit your manuscript at www.biomedcentral.com/submit 